Omni-Akuatika, 12 (3): 71-78,2016
ISSN: 1858-3873 print / 2476-9347 online
Research Article

\title{
Pengaruh Aerasi Injeksi Udara terhadap Beberapa Parameter Kualitas Air di Lokasi Budidaya Ikan Waduk Ir. H. Djuanda
}

\author{
Lismining Pujiyani Astuti ${ }^{1}$, Niken TM Pratiwi ${ }^{2)}$ \\ 1) Peneliti Balai Penelitian Pemulihan dan Konservasi Sumberdaya Ikan \\ 2) Fakultas Perikanan dan Kelautan, Institut Pertanian Bogor \\ Corresponding author : lisminingastuti@gmail.com
}

\begin{abstract}
Waste of fish farming in floating net are fish feces, urine and undigested feed which is one source of organic matter inputs in Ir. $\mathrm{H}$. Djuanda. Waste organic materials can cause eutrophication of waters. Air injection is one way aeration to increase oxygen to help the process of organic matter decomposition. The purpose of this study was to assess the effect of air injection on some parameters of water quality in fish farming side. This research was conducted at the location of fish farming Ir. H. Djuanda in June-September 2013. Injection of air using a compressor with a pressure of $3 \mathrm{~atm}$ as a source of air and perforated pipe at a depth of $3.6 \mathrm{~m}$. Air injection carried out for 8 hours. Observation point vertically at a depth of $3.6 \mathrm{~m}$ and horizontally at a distance of $-1.5 \mathrm{~m}$ (behind the diffuser pipe); 0 (the diffuser pipe); $1.5 \mathrm{~m}$ (right and left pipe); $+1.5 ;+3$ And $+6 \mathrm{~m}$ (in front of the pipe diffuser) and a distance of $17 \mathrm{~m}$ of pipe which is control. After eight hours of aeration showed that the concentration of organic matter, free carbondioxide, $\mathrm{N}-\mathrm{NO}_{2}$ tend to be lower in cages aerated but $\mathrm{N}-\mathrm{NO}_{3}$ concentration was higher in locations aeration cage than controls cage
\end{abstract}

Keywords: air injection aeration, water quality, fish cage culture, Ir. H. Djuanda Reservoir

\section{Pendahuluan}

\section{Latar belakang}

Kegiatan budidaya ikan melalui karamba jaring apung (KJA) yang terus bertambah berdampak terhadap tingkat kesuburan waduk yang juga semakin meningkat atau waduk telah mengalami eutrofikasi. Limbah dari kegiatan KJA terutama pakan yang tidak tercerna, feses dan urin yang dilepaskan secara langsung ke lingkungan perairan dapat menimbulkan permasalahan lingkungan seperti eutrofikasi, pertumbuhan ikan terhambat dan perubahan struktur komunitas bentos (Guo et al. 2009). Limbah KJA merupakan salah satu sumber bahan organik ke perairan. Kandungan bahan organik dalam jumlah cukup dapat menyuburkan perairan, namun jika jumlahnya banyak dapat mencemari perairan, kadar oksigen terlarut menurun, kadar $\mathrm{CO}_{2}$ meningkat dan terjadi kekeruhan (Cahyono 2001) yang dapat mempengaruhi keseluruhan struktur rantai makanan (food web) dan stabilitas ekosistem (Donk et al.
2008). Unsur hara yang berlebihan baik nitrogen dan fosfor yang dihasilkan dari kegiatan budidaya dapat menurunkan kualitas perairan. Pada keadaan ekstrim, penurunan kualitas perairan tersebut akan menyebabkan kematian ikan budidaya serta memacu timbulnya penyakit ikan.

Bakteria menggunakan oksigen untuk mendekomposisi bahan organik. Pada perairan yang tercemar, bakteria mengkonsumsi oksigen lebih cepat daripada produksi oksigen dari fotosintesis dan difusi atmosfer (Ji 2008). Philips et al. (1990) memperkirakan bahwa $85 \%$ fosfor dari pakan ikan masuk ke dalam lingkungan perairan. Pada kondisi aerob bakteri dapat mendekomposisi bahan organik dengan menggunakan oksigen terlarut dan menghasilkan fosfat dan pada keadaan anaerob fosfat akan dibebaskan.

Aerasi dengan injeksi udara adalah cara aerasi dengan memompakan udara ke dalam perairan yang bertujuan untuk meningkatkan oksigen sehingga dapat membantu mikrobia dalam proses 
dekomposisi bahan organik yang dihasilkan dari limbah KJA.

\section{Tujuan dan manfaat}

Tujuan penelitian ini adalah untuk mengkaji pengaruh injeksi udara terhadap beberapa parameter kualitas air di lokasi budidaya ikan. Hasil penelitian ini diharapkan aerasi dengan injeksi ini dapat menjadi salah satu teknik perbaikan kualitas perairan terutama di lokasi budidaya ikan

\section{Metodologi}

Waktu dan lokasi penelitian
Penelitian dilakukan pada bulan JuniAgustus 2013 di lokasi budidaya ikan dalam KJA di Waduk Ir. H. Djuanda, Jawa Barat, Indonesia (Gambar 1). Injeksi dilakukan selama 8 jam dengan sistem memompakan udara pada kedalaman $3,6 \mathrm{~m}$ yaitu kedalaman hipoksia menggunakan kompresor bertekanan $3 \mathrm{~atm}$. Pengambilan sampel air dilakukan setiap 3 jam sekali yaitu secara vertikal pada kedalaman 3,6 $\mathrm{m}$ dan secara horisontal pada jarak $-1,5 \mathrm{~m}$ (di belakang pipa diffuser); 0 (pada pipa diffuser); $1,5 \mathrm{~m}$ (sebelah kanan dan kiri pipa); $+1,5 ;+3$ dan +6 $\mathrm{m}$ (di depan pipa diffuser) serta jarak $17 \mathrm{~m}$ dari pipa yang merupakan control (Gambar 2).

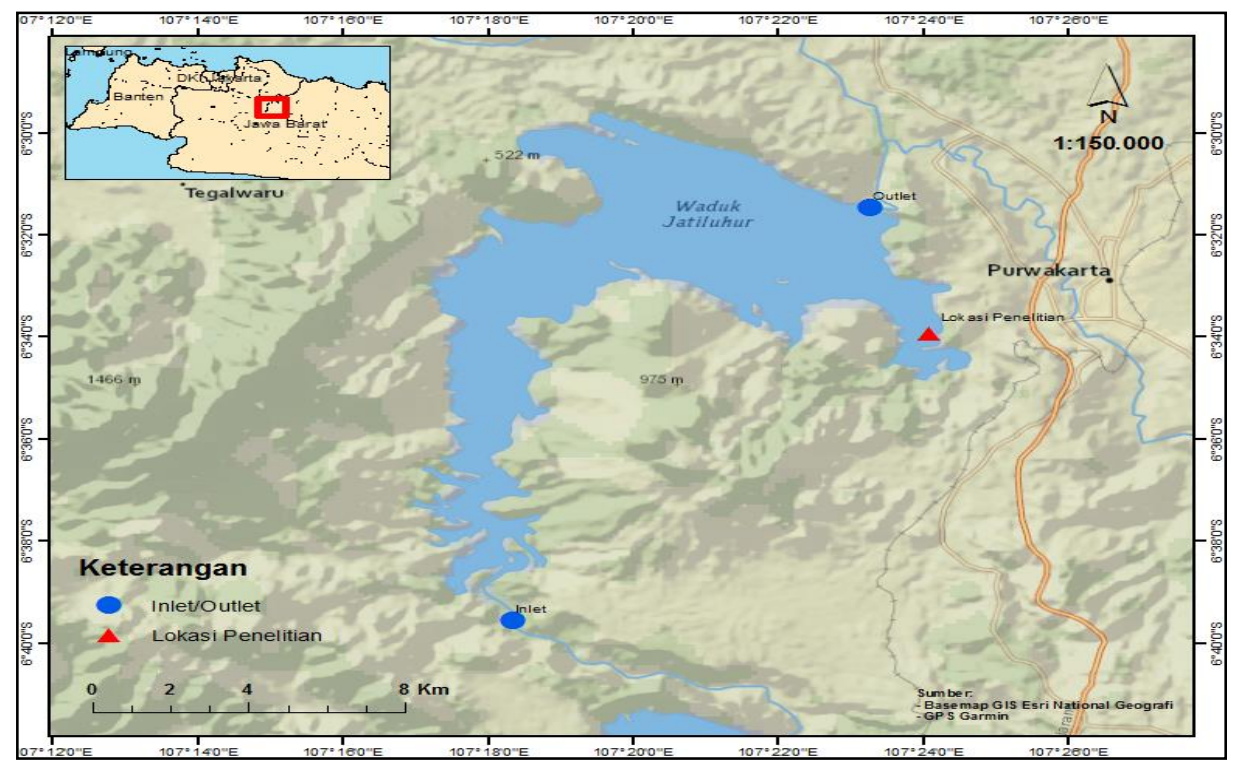

Gambar 1. Lokasi penelitian di waduk Ir. H. Djuanda

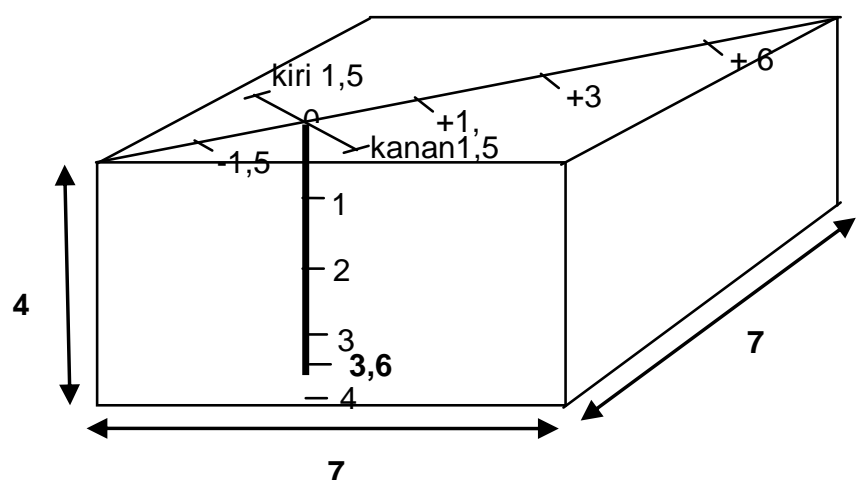

Gambar 2. Ukuran KJA (dalam meter) dan posisi pengukuran oksigen secara horizontal dan vertikal (dalam meter). 


\section{Spesifikasi alat aerasi}

Pipa aerasi yang digunakan adalah pipa PVC (Mobley and Brock, 1995) jenis AW yang kuat pada tekanan tinggi; berdiameter $3 / 4$ inch; ketebalan pipa $1,8 \mathrm{~mm}$ dan panjang pipa 3,7 $\mathrm{m}$. Lubang pipa dibuat pada kedalaman 3,6 $\mathrm{m}$ dengan diameter 2 $\mathrm{mm}$ yang bertujuan agar menghasilkan gelembung berukuran kecil. Sumber udara menggunakan kompresor $2 \mathrm{PK}$.

\section{Analisis parameter kualitas air}

Sampel air diambil dengan Kemmerer Water Sample bervolume $5 \mathrm{~L}$ kemudian dimasukan ke botol sampel untuk selanjutnya dianalisis di Laboratorium kualitas air Balai Penelitian Pemulihan dan Konservasi Sumberdaya Ikan.

Metode yang digunakan dalam analisis kualitas air

Tabel 1. Metode analisis parameter kualitas air

\begin{tabular}{llll}
\hline No & Parameter & Satuan & Metode/alat \\
\hline 1 & Bahan organik & $\mathrm{mg} / \mathrm{L}$ & Kalium permanganat -Titrimetri \\
2 & $\mathrm{P}-\mathrm{PO}_{4}$ & $\mathrm{mg} / \mathrm{L}$ & SnCl -Spectrofotometer \\
3 & $\mathrm{~N}-\mathrm{NH}_{4}$ & $\mathrm{mg} / \mathrm{L}$ & Nessler - Spectrofotometer \\
4 & $\mathrm{~N}-\mathrm{NO}_{2}$ & $\mathrm{mg} / \mathrm{L}$ & Naftilamine - Spectrofotometer \\
5 & $\mathrm{~N}-\mathrm{NO}_{3}$ & $\mathrm{mg} / \mathrm{L}$ & Brucine - Spectrofotometer \\
6 & $\mathrm{CO}_{2}$ & $\mathrm{mg} / \mathrm{L}$ & Natrium karbonat - titrimetri \\
\hline
\end{tabular}

\section{Hasil dan Pembahasan}

\section{Bahan organik total}

Bahan organik merupakan sumber nutrien bagi fitoplankton dan tumbuhan air. Bahan organik dapat didekomposisi dan menghasilkan unsur-unsur esensial bagi fitoplankton dan tumbuhan air seperti nitrogen, fosfor, kalium, kalsium serta unsur lainnya. Perombakan bahan organik memerlukan oksigen. Hasil pengamatan bahan organik total dan waktu aerasi sistem injeksi udara sebagai upaya peningkatan oksigen (Gambar 3).

Bahan organik berkisar 5,322-7,455 $\mathrm{mg} / \mathrm{L}$ dengan rerata $6,248 \pm 0,533 \mathrm{mg} / \mathrm{L}$. Konsentrasi tertinggi pada jarak $+6 \mathrm{~m}$ setelah 3 jam aerasi dan terendah pada jarak kanan 1,5 m setelah 3 jam aerasi.
Pada jarak $-1,5 \mathrm{~m}$ dan $+3 \mathrm{~m}$, konsentrasi bahan organik cenderung terus meningkat. Pada jarak $+1,5 \mathrm{~m} ;+6 \mathrm{~m}$; kiri 1,5 $\mathrm{m}$, konsentrasi bahan organik meningkat pada awal aerasi kemudian perlahan-lahan menurun hingga yang terendah setelah 8 jam aerasi. Konsentrasi bahan organik pada jarak kanan 1,5 m cenderung berfluktuasi. Konsentrasi bahan organik pada jarak $0 \mathrm{~m}$ cenderung terus menurun sedangkan pada kontrol cenderung terus meningkat walau peningkatannya kecil seperti pendapat Avnimelech et al. (1992) bahwa kandungan bahan organik relatif lebih tinggi pada kontrol daripada yang diaerasi walaupun hasil pengamatan terdapat beberapa titik yang lebih tinggi daripada kontrol. Hal ini dapat dipahami karena pada titik tersebut tidak mendapat suplai oksigen yang mencukupi untuk mendekomposisi bahan organik. 


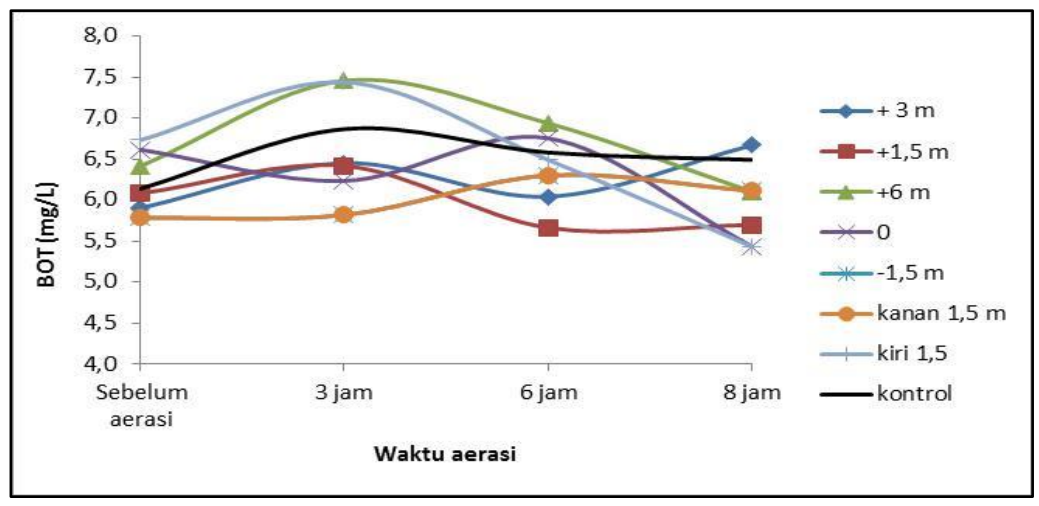

Gambar 3. Konsentrasi bahan organik total (BOT) selama aerasi

Menurut Simarmata (2007), konsentrasi bahan organik total yang aman diterima di zona transisi (zona yang terdapat kegiatan budidaya dalam KJA) di Waduk Ir. H. Djuanda pada musim kemarau 4,480 mg/L; antara musim kemarau-hujan 7,760 $\mathrm{mg} / \mathrm{L}$ dan pada musim hujan 4,240 mg/L. Apabila konsentrasi bahan organik yang diterima melebihi konsentrasi tersebut dapat menyebabkan terjadinya defisit oksigen. Pada pengamatan ini, bahan organik sebelum aerasi pada lokasi karamba aerasi berkisar antara 5,7-6,73 mg/L dengan rerata $6,17 \mathrm{mg} / \mathrm{L}$ dan pada kontrol sebesar 6,14 $\mathrm{mg} / \mathrm{L}$ yang artinya sudah melebihi batas aman konsentrasi bahan organik yang dapat diterima di lokasi budidaya ikan Waduk Ir. H. Djuanda.

Bahan organik yang lebih tinggi pada lokasi aerasi sejalan dengan hasil penelitian Gawronska et al. (2003) yang menyebutkan bahwa bahan organik pada stasiun yang diaerasi lebih tinggi yaitu 40-50 mg/L daripada stasiun yang tidak diaerasi yaitu 20-40 mg/L. Hal tersebut diduga karena adanya allocthonous organic matter suspended solid dan bahan organik yang belum terendapkan yang terbawa dari jarak jauh dan mengendap pada stasiun tersebut. Bahan organik yang tinggi ini ditandai dengan adanya deplesi oksigen. Perlu aerasi yang lama agar bahan organik dapat menurun. Proses aerasi merupakan upaya peningkatan oksigen agar proses dekomposisi bahan organik secara aerobik dapat berlangsung dengan baik. Tingginya bahan organik yang telah melebihi batas aman menyebabkan kebutuhan oksigen untuk proses dekomposisi juga lebih besar. Pemberian pakan secara intensif pada sistem budidaya ikan dapat menyebabkan tingginya penyerapan oksigen (Avnimelech et al., 1992).

Hasil penelitian Sunanisari (1993) dengan aerasi selama 17 jam sehari menunjukkan bahwa bahan organik menurun dari awal pengamatan hingga 42 hari aerasi pada jarak 5-9 m dari pusat aerator tetapi cenderung meningkat pada jarak 11-19 m. Menurut Dauve et al. (2001), dekomposisi bahan organik bergantung pada oksigen, komposisi kimia dari bahan organik dan laju dekomposisi bahan organik.

\section{Orthofosfat $\left(\mathrm{P}-\mathrm{PO}_{4}\right)$}

Fosfor merupakan hara penting untuk tumbuhan air dan alga dan juga merupakan salah satu faktor pembatas untuk pertumbuhan alga. Namun demikian, apabila jumlahnya banyak dapat menjadi suatu permasalahan bagi perairan. Fosfor yang berlebihan dapat menyebabkan terjadinya blooming alga yang tidak terkendali atau terjadi eutrofikasi. Orthofosfat merupakan bentuk fosfor yang langsung dapat dimanfaatkan oleh fitoplankton dan makrofita akuatik. Hasil pengamatan konsentrasi orthofosfat disajikan pada Gambar 4. 


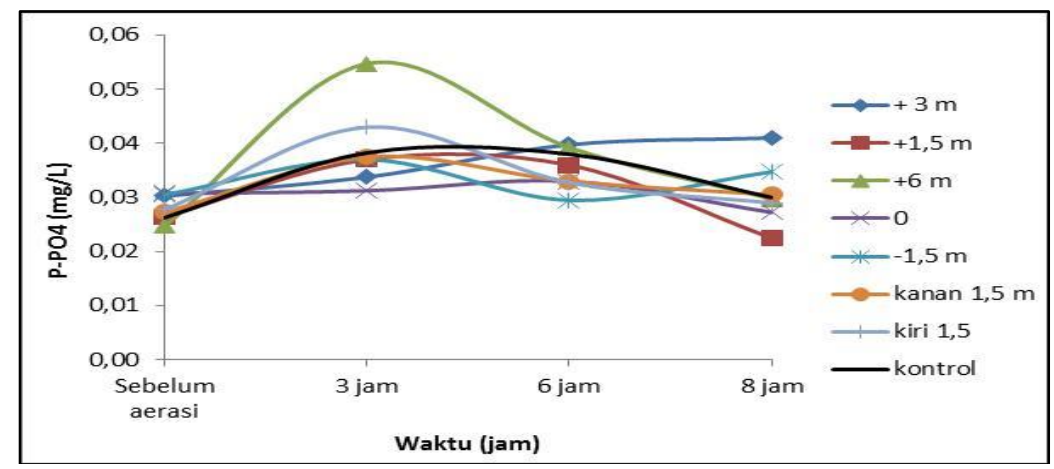

Gambar 4. Konsentrasi $\mathrm{P}-\mathrm{PO}_{4}$ selama aerasi

\section{Konsentrasi orthofosfat berkisar 0,023-0,055 $\mathrm{mg} / \mathrm{L}$ dengan rerata} $0,033 \pm 0,0064 \mathrm{mg} / \mathrm{L}$. Berdasarkan Gambar 4 menunjukkan bahwa konsentrasi tertinggi terjadi pada titik $+6 \mathrm{~m}$ setelah 3 jam aerasi dan konsentrasi terendah terjadi pada titik + $1,5 \mathrm{~m}$ setelah 8 jam aerasi. Pada titik $+1,5$ $\mathrm{m} ;+6 \mathrm{~m}$; 0; kanan $1,5 \mathrm{~m}$ dan kiri $1,5 \mathrm{~m}$ cenderung naik pada awal aerasi kemudian perlahan-lahan terus menurun. Pada jarak $+1,5 \mathrm{~m}$ cenderung berfluktuasi sementara pada jarak $+3 \mathrm{~m}$ dan kontrol cenderung terus meningkat. Hasil penelitian ini seperti hasil penelitian Ujang et al. (2002) bahwa konsentrasi $\mathrm{PO}_{4}$ berfluktuasi selama aerasi. Ashley (1983) menyebutkan bahwa aerasi selama dua minggu di hipolimnion Danau Black menyebabkan penurunan $\mathrm{P}-\mathrm{PO}_{4}$ pada hipolimnion. Hasil penelitian Verma and Dixit (2006) di Danau Lower, India menunjukkan bahwa selama aerasi, konsentrasi fosfat di permukaan perairan menurun sementara di dasar perairan meningkat yang diduga di dasar perairan ini mendapatkan tambahan fosfat dari pelepasan fosfat dasar perairan. Berdasarkan United States Environment Protection Agency (USEPA, ketersedian ortofosfat maksimal $0,085 \mathrm{mg} / \mathrm{L}$ sebagai batas kritis untuk eutrofikasi perairan (Verma and Dixit 2006), sehingga konsentrasi ortofosfat di Waduk Ir. H. Djuanda masih dalam batas yang tidak menyebabkan eutrofikasi yaitu $<0,085 \mathrm{mg} / \mathrm{L}$. Namun menurut Volenweider dalam Effendi (2003), konsentrasi orthofosfat yang dapat menyebabkan eutrofikasi adalah 0,031-0,1 $\mathrm{mg} / \mathrm{L}$ sehingga Waduk Ir. H. Djuanda dapat dikatakan telah menuju waduk yang bersifat eutrofik atau meso eutrofik.

\section{Karbondioksida bebas $\left(\mathrm{CO}_{2}\right)$}

Berdasarkan Gambar 5 menunjukkan bahwa konsentrasi $\mathrm{CO}_{2}$ menurun sejalan dengan lama aerasi pada semua titik pengamatan sedangkan pada kontrol cenderung tidak mengalami perubahan. Ini menunjukkan bahwa adanya aerasi dapat meningkatkan oksigen dan menurunkan konsentrasi karbondioksida. Konsentrasi $\mathrm{CO}_{2}$ berkisar 2,1 - 3,6 mg/L. Di Danau Brooker, aerasi secara nyata dapat menurunkan konsentrasi $\mathrm{CO}_{2}$ dengan ratarata harian 3,61 mg/L (Cowell et al., 1987). Ashley (1983) menyebutkan bahwa konsentrasi karbon dioksida menurun setelah aerasi selama dua minggu sementara untuk lokasi tanpa aerasi, konsentasi karbondioksida meningkat. 


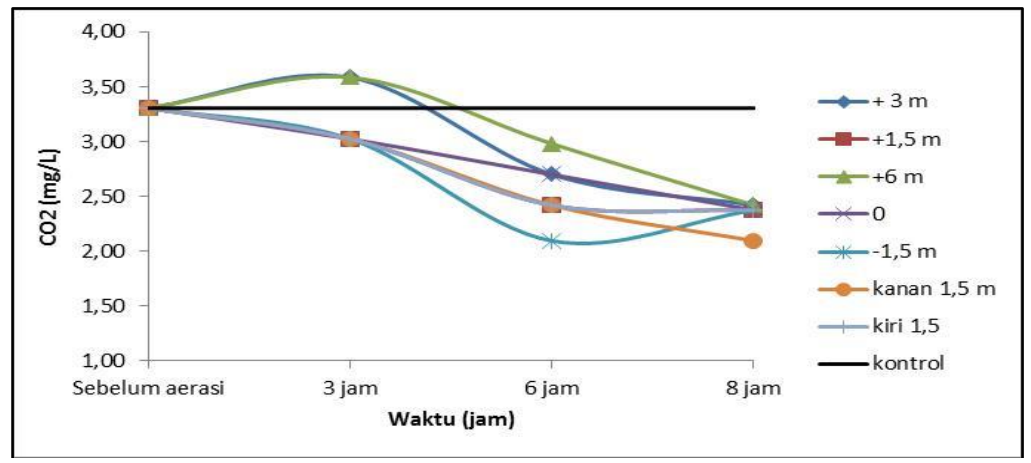

Gambar 5. Konsentrasi $\mathrm{CO}_{2}$ bebas selama proses aerasi

\section{Nitrogen}

Konsentrasi $\quad \mathrm{N}-\mathrm{NH}_{4} \quad$ cenderung berfluktuasi, hal ini diduga karena amonium merupakan ion yang labil sehingga mudah berubah. Ion $\mathrm{NH}_{4}$ cenderung mudah berubah pada kondisi aerob menjadi $\mathrm{NO}_{2}$ atau terjadi proses nitrifikasi. Aerasi dapat meningkatkan aktivitas nitrifikasi oleh bakteri di kolom air sehingga $\mathrm{NH}_{4}$ menurun (Jamienson et al., 2003). Dalam pengamatan ini, konsentrasi $\mathrm{NH}_{4}$ berfluktuasi (Gambar 6a). Pada jarak $+1,5$ $\mathrm{m}$, konsentrasi $\mathrm{NH}_{4}$ cenderung menurun. Konsentrasi $\mathrm{N}-\mathrm{NH}_{4}$ berkisar 0,37 - 0,598 $\mathrm{mg} / \mathrm{L}$.

Konsentrasi $\quad \mathrm{N}-\mathrm{NO}_{2} \quad$ cenderung berfluktuasi dan paling tinggi terjadi pada titik 0 setelah 6 jam aerasi (Gambar $6 b$ ). Konsentrasi $\mathrm{N}-\mathrm{NO}_{2}$ berkisar 0,006 - 0,028 $\mathrm{mg} / \mathrm{L}$ dan tertinggi pada jarak $0 \mathrm{~m}$ setelah 6 jam aerasi. Pada akhir aerasi lokasi kontrol mempunyai konsentasi $\mathrm{N}-\mathrm{NO}_{2}$ lebih tinggi dibanding titik pengamatan lainnya. Hal ini diduga, dengan adanya aerasi maka ada tambahan oksigen yang akan membantu proses oksidasi nitrit menjadi nitrat (nitratasi) sehingga nitrit berkurang pada lokasi aerasi. Konsentrasi $\mathrm{N}-\mathrm{NO}_{3}$ cenderung lebih tinggi pada karamba yang diaerasi daripada karamba kontrol (Gambar 6c) yang sejalan dengan penelitian Ashley (1983) di Danau Black, Colombia. Sakatani et al. (2006) juga menyebutkan bahwa terjadi peningkatan N$\mathrm{NO}_{3}$ di Danau Sugo, Kyoto setelah diaerasi. Konsentrasi $\mathrm{N}-\mathrm{NO}_{3}$ berkisar 0,452 - 0,821 $\mathrm{mg} / \mathrm{L}$ dan tertinggi pada jarak $+6 \mathrm{~m}$ setelah 3 jam aerasi.

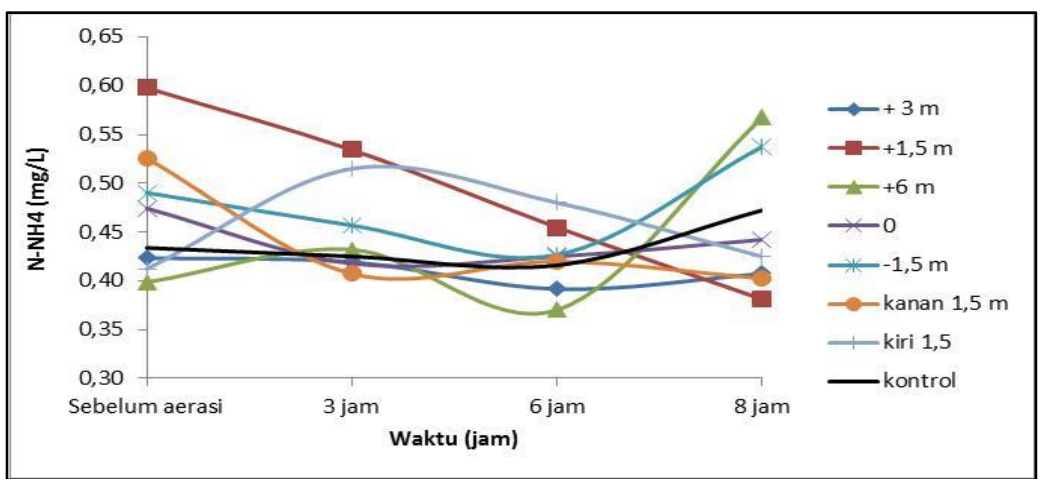

(a) 


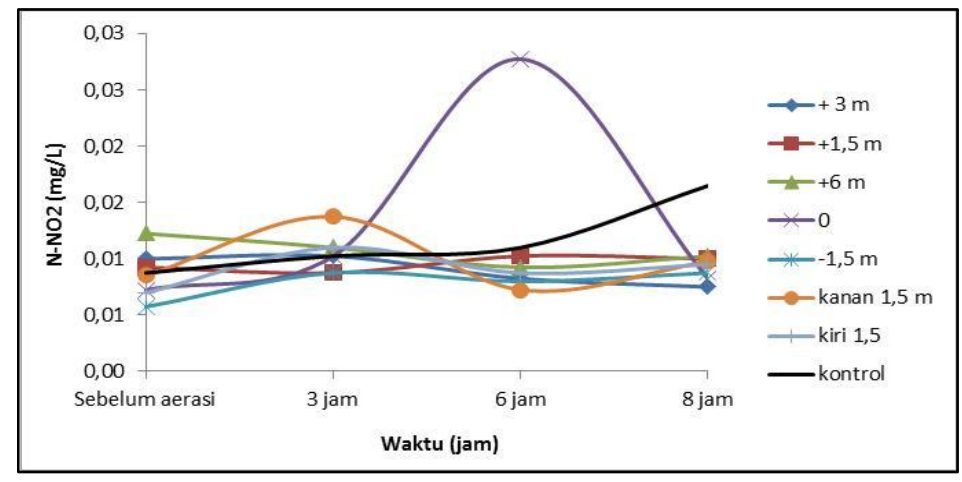

(b)

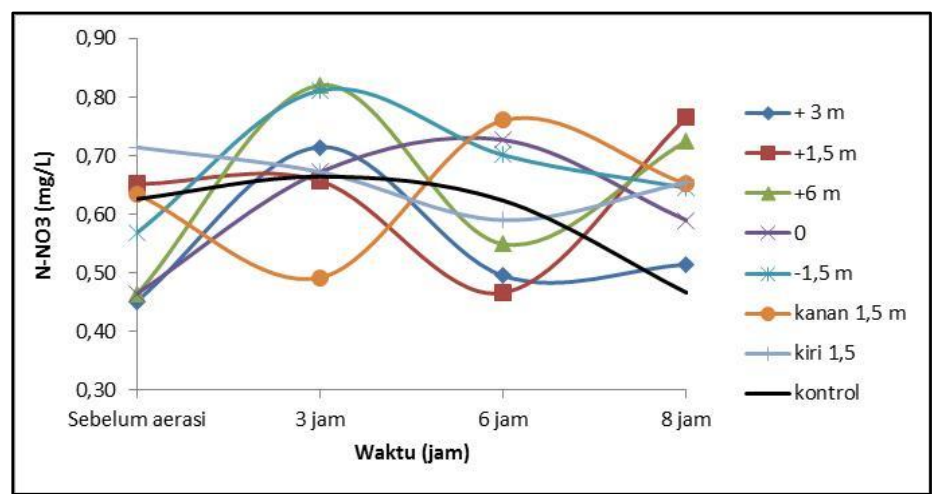

(c)

Gambar 6. Konsentrasi (a) $\mathrm{N}-\mathrm{NH}_{4}$, (b) $\mathrm{N}-\mathrm{NO}_{2}$ dan (c) $\mathrm{N}-\mathrm{NO}_{3}$ selama aerasi

\section{Kesimpulan}

Konsentrasi bahan organik berkisar 5,322-7,455 mg/L. Setelah delapan jam aerasi, bahan organik pada karamba yang diaerasi cenderung lebih rendah dibandingkan karamba kontrol. Konsentrasi ortofosfat berkisar 0,023-0,055 mg/L dan berfluktuasi selama proses aerasi. Setelah delapan jam aerasi karbondioksida bebas pada karamba aerasi cenderung lebih rendah daripada karamba kontrol. Konsentrasi $\mathrm{N}-\mathrm{NH}_{4}$ cenderung berfluktuasi selama aerasi sementara konsentrasi $\mathrm{N}-\mathrm{NO}_{2}$ cenderung lebih tinggi pada karamba kontrol dan konsentrasi $\mathrm{N}-\mathrm{NO}_{3}$ cenderung lebih tinggi pada lokasi karamba aerasi. Aerasi dengan injeksi udara dapat menurunkan bahan organik, karbondioksida bebas namun meningkatkan $\mathrm{N}-\mathrm{NO}_{3}$.

\section{Daftar Pustaka}

Ashley, K.I. 1983. Hypolimnetic aeration of a natural eutrophic lake: Physical and chemical effect. Canadian Journal of Fisheries and Aquatic Sciences 40 : 1343-1359.

Avnimelech, Y., Mozes, N., Diab, S., Kochba, M. 1995. Rate of organic carbon and nitrogen degradation in intensive fish pond. Aquaculture 134: 211-216.

Cahyono, B. 2006. Budidaya ikan di perairan umum. Penerbit Kanisius, Yogayakarta. 95 hal

Cowell, B.C., Dawes, C.J., Gardiner, W.E., Scheda, S.M. 1987. The influence of whole lake aeration on the limnology of a hypereutrophic lake in central Florida. Hydrobiologia 148:3-24

Dauve, B., Middleburg, J.J., Herman, P.M.J. 2001. Effect of the oxygen on the degradability of organic matter in subtidal and intertidal sediment on the north Sea area. Marine Ecology Progress Service 215: 13-21. 
Donk, E.V., Hessen, D.O., Verschoora, A.M., Gulati, R.D. 2008. Reoligotrophication by phosphorus reduction and effects on seston quality in lakes. Limnologica 38: 189202.

Effendi, H. 2003. Telaah Kualitas Air : Pengelolaan Sumberdaya Perairan dan Lingkungan. Kanisius. Yogyakarta. p 250

Gawroska, H., Brzozowska, R., Grochowska, J., Lossow, K. 2003. Possibilities reduce internal loading to water by artificial aeration. Polish Journal of Environmental Studies 12 (2): 171-179

Guo, L., Li, Z., Xie, P., Ni, L. 2009. Assessment effects of cage culture on nitrogen and phosphorus dynamics in relation to fallowing in a shallow lake in China. Aquaculture International 17: $229-241$

Jamienson, T.S., G.W. Stratton, R. Gordon, A. Madani. 2003. The use of aeration to enhance ammonia nitrogen removal in constructed wetland. Canadian Biosystem Engineering 45: $1.9-1.13$

Ji, Z.G. 2008. Hydrodynamics and Water Quality: Modelling Rivers, Lakes, and Estuaries. Wiley Interscience. p 675

Michioku, K., Y. Sakatani, K. Matsuo, T. Oda and Y. Hara. 2006. Reservoir purification by using micro bubble aeratorThe $7^{\text {th }}$ Int. Conf on Hydroscience and Engineering (ICHE2006), Philadelphia, USA

Mobley, M.H., Brock, W.G. 1995. Widespread Oxygen bubble to improve reservoir release. Lake and Management II (3): 231-234.

Philips, M.J., Beveridge, M.C.M., Macintosh, D.J. 1990. The impact of aquaculture on the coastal environment. Proceedings of ISCZC

Simarmata, A.H. 2007 Kajian keterkaitan antara kemantapan cadangan oksigen dengan beban masukan bahan organik di Waduk Ir. H. Juanda Purwakarta, Jawa Barat. Disertasi. Sekolah Pasca Sarjana IPB, Bogor. p 141.
Sunanisari, S. 1993. Experimantal aeration with Limnotek 3.1, impact on organic matter and ammonia. Limnotek 1 (1): 47-52

Ujang, Z.M.R, Salim, Khor, S.I. 2002. The effect of aeration and non aeration time on simultaneaous organik, nitrogen and phosphorus removal using an intermittent aeration aeration membrane bio reactor. Water Science and Technology 46 (9): 193-200.

Verma, N., Dixit, S. 2006. Effectiviness of aeration units in improving water quality of Lower Lake, Bophal, India. Asian Journal of e"xperimental Sciences 20 (1): 87- 95. 